\title{
APLIKASI PENGELOLAAN DATA PRAKTIKUM LABORATORIUM KOMPUTER STMIK WIDYA CIPTA DHARMA BERBASIS INTRANET
}

\author{
Awang Harsa Kridalaksana ${ }^{1)}$, Salmon ${ }^{2)}$, Muhammad Beny Hafis ${ }^{3)}$ \\ ${ }^{1}$ Teknik Informatika, STMIK Widya Cipta Dharma \\ ${ }^{2,3}$ Sistem Informasi, STMIK Widya Cipta Dharma \\ 1,2,3 J1. Prof. M. Yamin No. 25, Samarinda, 75123 \\ E-mail : awangkid@gmail.com ${ }^{1)}$,sal_msp@yahoo.co.id ${ }^{2)}$,informatikawicida@gmail.com ${ }^{3)}$
}

\begin{abstract}
ABSTRAK
UPT. Laboratorium komputer STMIK Widya Cipta Dharma merupakan sebuah unit kerja yang memberikan pelayanan akademik. Laboratorium Komputer mempunyai fungsi sebagai tempat proses pembelajaran. Dalam kegiatan praktikum pada laboratorium komputer mahasiswa menggunakan komputer tetap dalam praktikum mata kuliah tersebut karena datadata praktikum hanya ada pada komputer tersebut tanpa mempunyai penyimpanan data yang baik. Apabila mahasiswa maupun dosen ingin meminta data-data tersebut meraka harus menghubungi admin laboratorium tersebut mendapatkan data-data praktikum tersebut lalu membuka komputer mahasiswa tersebut untuk disalin data-datanya. Hal ini tidak efisien dalam melakukan pertukaran data ditambah komputer digunakan oleh banyak mahasiswa membuat data-data praktikum menumpuk dan dapat tercampur dengan data mahasiswa lain.
\end{abstract}

Penelitian ini dibuat untuk mengatasi berbagai kendala yang dihadapi oleh Laboratorium Komputer STMIK WICIDA. Dalam membangun aplikasi ini menggunakan metode pengembangan sistem waterfall, metode pengujian blackbox dan pengujian beta, database MYSQL dan menggunakan bahasa pemrograman PHP (PHP Hypertext Preprocessor), dreamweaver sebagai webeditor, apache sebagai webserver local, flowchart, Data Flow Diagram dan Entity Relationship Diagram sebagai alat bantu perancangan sistem.

Dengan adanya aplikasi pengelolaan data praktikum berbasis intranet ini diharapkan dapat membantu laboratorium komputer STMIK WICIDA dan memberikan kemudahan dalam pengelolaan data praktikum.

Kata Kunci: Aplikasi, Pengelolaan, Data, Praktikum, Intranet

\section{PENDAHULUAN}

UPT. Laboratorium komputer STMIK Widya Cipta Dharma merupakan sebuah unit kerja yang memberikan pelayanan akademik. Laboratorium Komputer mempunyai fungsi sebagai tempat proses pembelajaran dengan metode praktikum yang dapat memberikan pengalaman belajar pada mahasiswa untuk berinteraksi dengan komputer.

Kegiatan laboratorium atau praktikum akan memberikan peran yang sangat besar agar dapat menjadikan praktikan sebagai mahasiswa yang mampu bersaing di dunia IPTEK dan menghasilkan inovasi teknologi yang berguna bagi masyarakat berdasarkan ilmu yang didapatkan.

Dalam kegiatan praktikum pada laboratorium komputer mahasiswa menggunakan komputer tetap dalam praktikum mata kuliah tersebut karena data-data praktikum hanya ada pada komputer tersebut tanpa mempunyai penyimpanan data yang baik. Apabila mahasiswa maupun dosen ingin meminta data-data tersebut meraka harus menghubungi admin laboratorium tersebut mendapatkan data-data praktikum tersebut lalu membuka komputer mahasiswa tersbut untuk disalin data-datanya. Hal ini tidak efisien dalam melakukan pertukaran data ditambah komputer digunakan oleh banyak mahasiswa membuat data-data praktikum menumpuk dan dapat tercampur dengan data yang lain.

Dari latar belakang masalah tersebut, maka agaer dapat membantu menyelesaikan permasalahan tersebut, dibuat suatu aplikasi untuk mengelola data praktikum laboratorium komputer STMIK Widya Cipta Dharma berbasis intranet dan sebagai penyimpanan data praktikum yang lebih baik.

\section{RUANG LINGKUP PENELITIAN}

Permasalahan difokuskan pada:

1. Halaman Kepala Lab merupakan halaman bagi Kepala Lab mengelola data sistem seperti menambah, mengubah dan menghapus data user, data program studi, data tahun ajaran, data mata kuliah pada aplikasi. Upload file, download file, tambah file baru, hapus file dan tambah folder baru serta melakukan pencarian data atau folder serta membuat kelompok..

2. Halaman Staff Lab merupakan halaman bagi Staff Lab mengelola data sistem seperti menambah, mengubah dan menghapus data user, data program studi, data tahun ajaran, data mata kuliah pada aplikasi. Upload file, download file, tambah file baru, hapus file dan tambah folder baru serta melakukan pencarian data atau folder serta membuat kelompok. 
3. Halaman Asisten Lab merupakan halaman bagi Asisten Lab untuk mengubah data mata kuliah, mengunci folder serta mendownload semua data praktikum berdasarkan mata kuliah dan membuat kelompok serta daftar mahasiswa pada kelompok tersebut.

4. Halaman Mahasiswa merupakan halaman untuk mahasiswa melakukan Upload file, download file, tambah file baru, hapus file, dan melakukan pencarian data atau folder.

5. Metode pengembangan sistem yang digunakan adalah metode waterfall dengan pengujian black box dan beta.

6. Aplikasi dibangun menggunakan bahasa pemrograman PHP, HTML, Javascript dan MySQL sebagai database.

7. Aplikasi tidak membahas penjadwalan, penilaian serta absensi praktikum.

8. Data praktikum/mahasiswa dan mata kuliah praktikum diinput dalam aplikasi (tidak dikonversidari data SIAK STMIK Widya Cipta Dharma

\section{BAHAN DAN METODE}

Adapun bahan dan metode yang digunakan dalam web ini, yaitu:

\subsection{Model Air Terjun}

Menurut Rosa dan Shalahuddin (2011), Model SDLC air terjun (Waterfall) sering juga disebut model sekuensial linier (sequential linear) atau alur hidup klasik (classic life cycle). Model air tejun menyediakan pendekatan alur hidup perangkat lunak secara sekuensial atau terurut.dimulai dari analisis, desain, pengodean, pengujian, dan tahap pendukung (support) atau pemeliharaan (maintenance). Berikut adalah tahapantahapan dalam metode tersebut:

1. Analisis

Proses pengumpulan kebutuhan dilakukan secara intensif untuk menspesifikasikan kebutuhan perangkat lunak agar dapat dipahami perangkat lunak apa yang dibutuhkan oleh user. Spesifikasi kebutuhan perangkat lunak pada tahap ini diperlukan untuk didokumentasikan. 2. Desain

Desain perangkat lunak adalah proses multi langkah yang berfokus pada desain pembuatan program perangkat luak termasuk struktur data, arsitektur perangkat lunak, representasi antarmuka, dan prosedur pengkodean. Tahap ini mentranslasi kebutuhan perangkat lunak dari tahap analisi kebutuhan ke representasi desain agar dapat diimplementasikan menjadi program pada tahap selanjutnya. Desain perangkat lunak yang dihasilkan pada tahap ini juga perlu didokumentasikan.

3. Implementasi

Desain harus ditranslasikan ke dalam program perangkat lunak. Hasil dari tahap ini adalah komputer sesuai dengan desain yang telah dibuat pada tahap desain.

4. Pengujian
Pengujian berfokus pada perangkat lunak dari segi logik dan fungsional dan memastikan bahwa semua bagian sudah diuji. Ini dilakukan untuk meminimalisir kesalahan dan memastikan keluaran yang dihasilkan sesuai dengan apa yang diinginkan oleh pengguna.

5. Pemeliharaan (maintenance)

Tidak menutup kemungkinan sebuah perangkat lunak mengalami perubahan ketika sudah dikirim ke user. Perubahan bisa terjadi kerena adanya kesalahan yang muncul dan tidak terdeteksi saat pengujian atau perangkat lunak harus beradaptasi dengan lingkungan baru.

\section{RANCANGAN SISTEM/APLIKASI}

Berikut ini adalah contoh berbagai perancangan desain yang digunakan:

\subsection{Flowchart Kepala Lab/Staff Lab}

Flowchart kepala Lab dan Staff Lab dimulai pada halaman login user lalu menginput username dan password jika username dan password yang diinputkan benar maka akan masuk ke halaman dashboard, lalu menambah user jika ya maka input data user lalu proses dan disimpan pada tabel user begitu juga jika ingin menambah data prodi, tahun ajaran, kelompok, mahasiswa dalam kelompok dan mata kuliah. Jika ingin mendownload maka ya jika tidak maka selesai. flowchart kepala lab dapat di lihat pada gambar 1 :

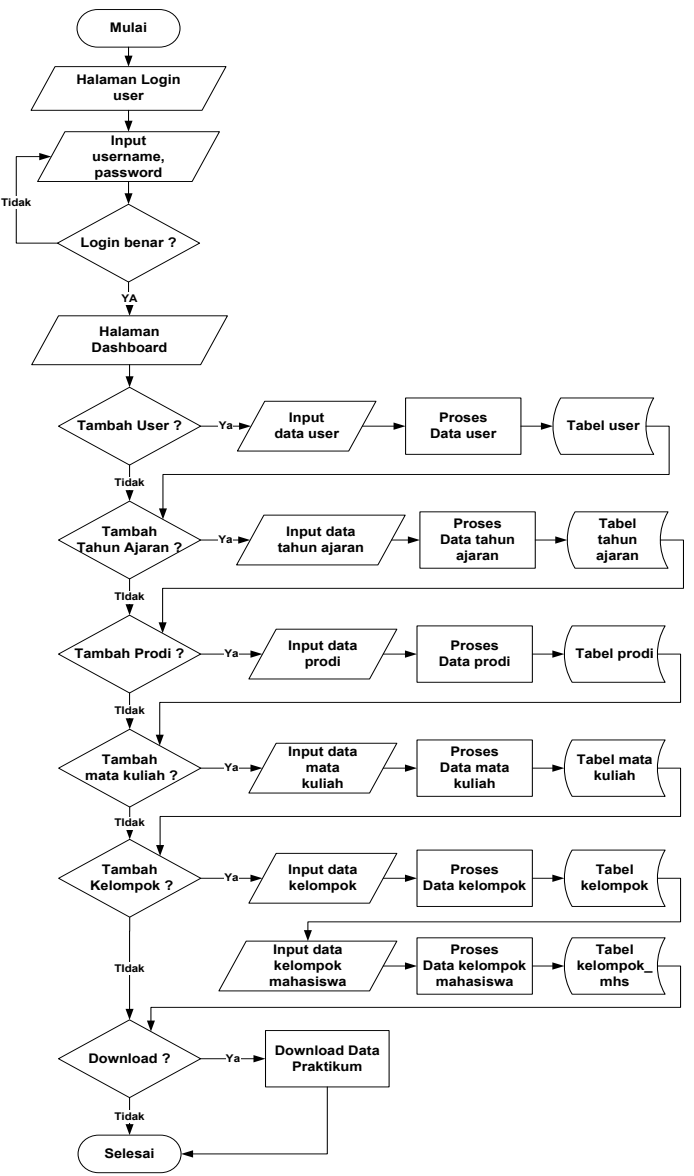

Gambar 1. Flowchart Kepala Lab/Staff Lab 


\subsection{Flowchart Asisten Lab}

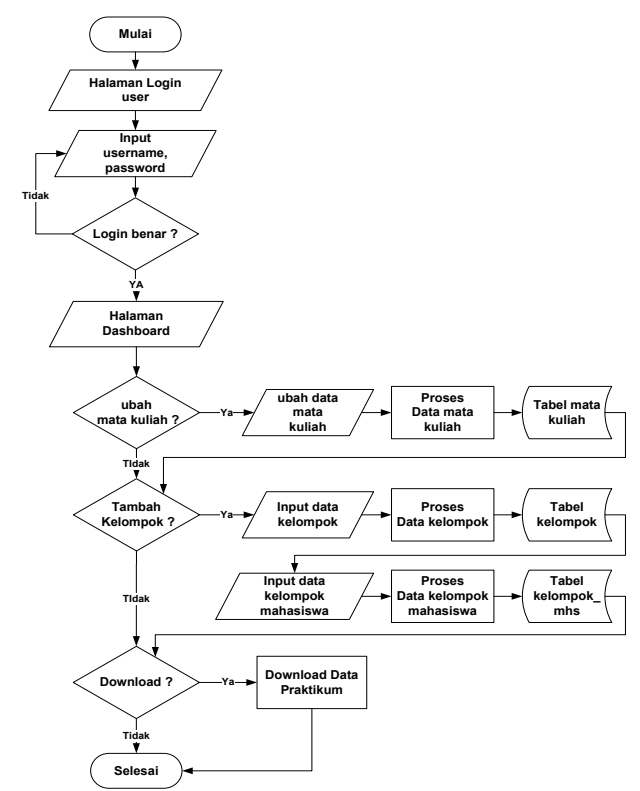

Gambar 2. Flowchart Asisten Lab

Flowchart asisten lab dimulai pada halaman login user lalu menginput username dan password jika username dan password yang diinputkan benar maka akan masuk ke halaman dashboard, lalu dapat mengubah data mata kuliah menambah kelompok, mahasiswa dalam kelompok. Jika ingin mendownload maka ya jika tidak maka selesai.

\subsection{Flowchart Mahasiswa}

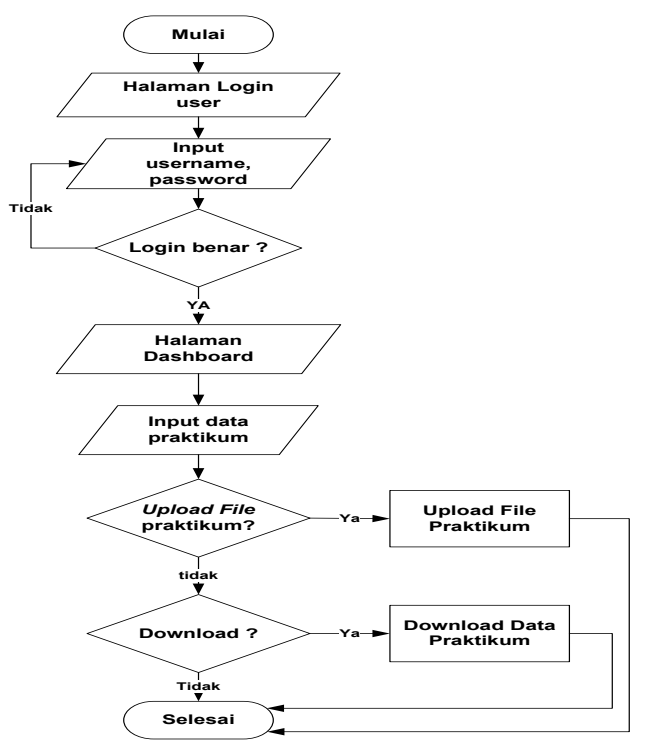

Gambar 3. Flowchart Mahasiswa
Flowchart mahasiswa dimulai pada halaman login user lalu menginput username dan password jika username dan password yang diinputkan benar maka akan masuk ke halaman dashboard, lalu mahasiswa membuat folder praktikum dan menginputkan data file praktikumnya. Upload file praktikum jika ya maka kembali upload file praktikum. Jika ingin mendownload maka ya, jika tidak maka selesai.

\subsection{Context Diagram (CD)}

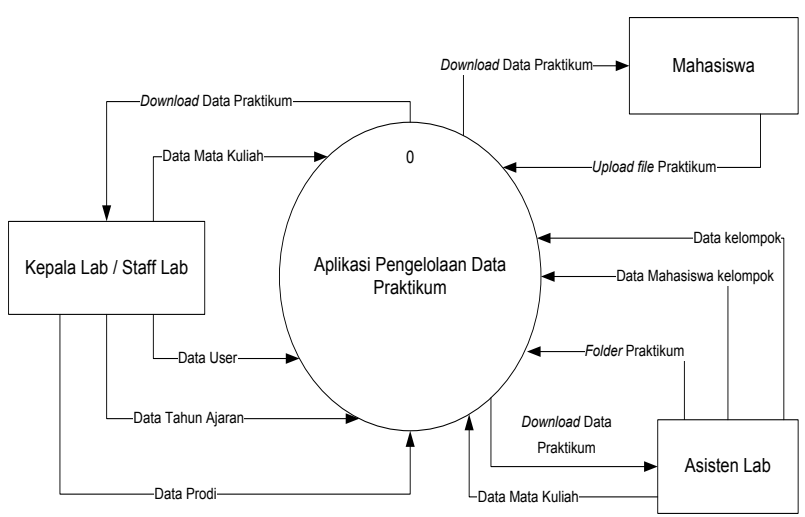

Gambar 4. Context Diagram (CD)

Context diagram aplikasi pengelolaan data praktikum. Kepala Lab atau Staff admin meninputkan data user, data prodi, data tahun ajaran dan data mata kuliah dan dapat mendownload data praktikum. Mahasiswa mengupload file praktikum dan dapat mendownload data praktikum tersebut. Asisten Lab dapat mengubah data mata kuliah dan mendownload file praktikum dan membuat kelompok serta mahasiswa pada kelompok tersebut.

\subsection{Diagram Nol/Zero}

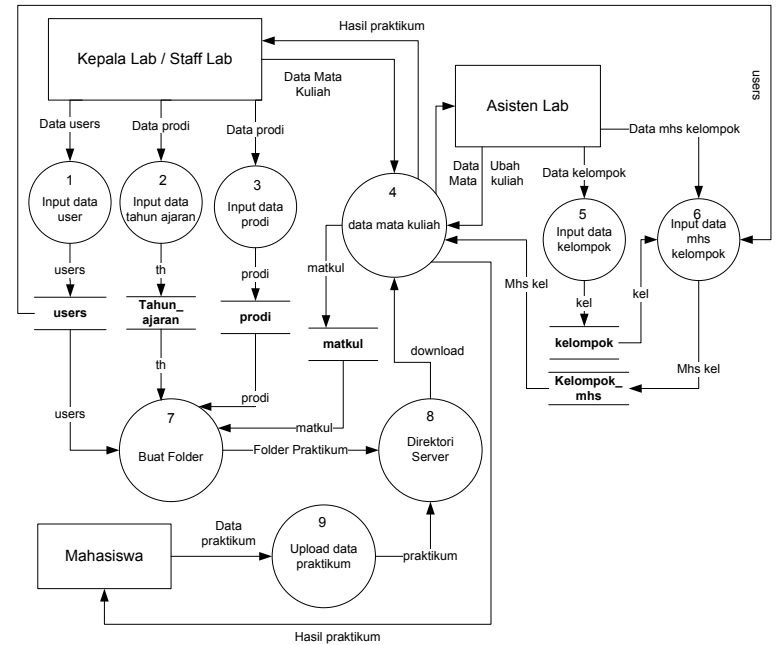

Gambar 5. Diagram Nol/Zero

Berikut adalah penjelasan dari Diagram nol/zero. Kepala Lab atau Staff menginputkan data user lalu di 
simpan pada datastore users, data tahun ajaran disimpan pada datastore tahun_ajaran, data prodi disimpan pada datastore prodi, data mata kuliah disimpan pada datastore matkul. Asisten lab dapat mengubah data mata kuliah disimpan pada datastore matkul dan mendapatkan hasil praktikum, membuat kelompok dan menginputkan data mahasiswanya yang disimpan pada datastore kelompok dan kelompok_mhs. Mahasiswa, Kepala lab/staff lab dan asisten lab dapat mendownload data praktikum dari direktori server dan mendapat hasil praktikum. Mahasiswa mengupload data praktikum ke folder praktikum yang disimpan pada direktori server.

\subsection{Diagram Rinci}

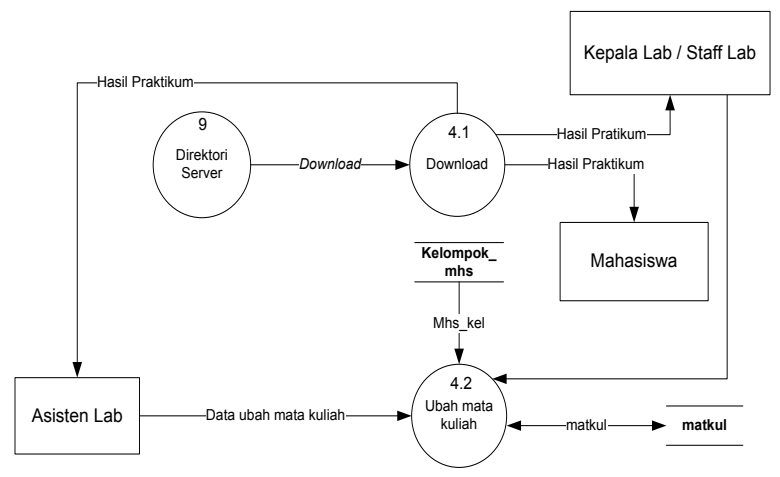

Gambar 6. Diagram Rinci

Berikut adalah penjelasan dari diagram rinci dari direktori server diproses download data praktikum dengan output hasil praktikum yang didapat oleh kepala lab/staff lab, asisten lab dan mahasiswa. Asisten lab dapat mengubah data mata kuliah dengan menginputkan data mata kuliah berdasarkan data pada datastore matkul lalu diproses dan tersimpan pada datastore matkul.

\subsection{HIPO}

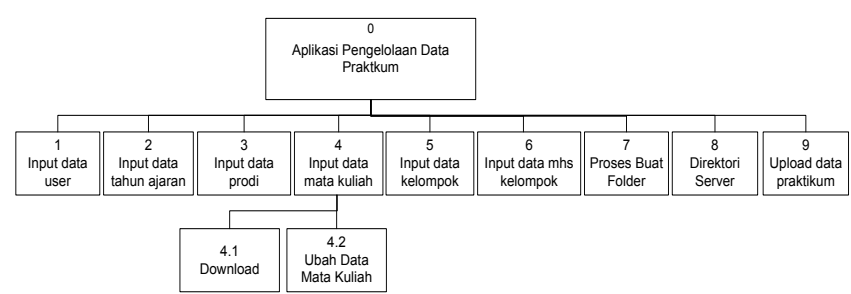

\section{Gambar 7. HIPO}

HIPO terdiri dari input data user, data tahun ajaran, data prodi, data mata kuliah, data kelompok dan data mhs kelompok. Proses download, ubah mata kuliah, buat folder, direktori server dan upload data praktikum.

\subsection{Entity Relationship Diagram}

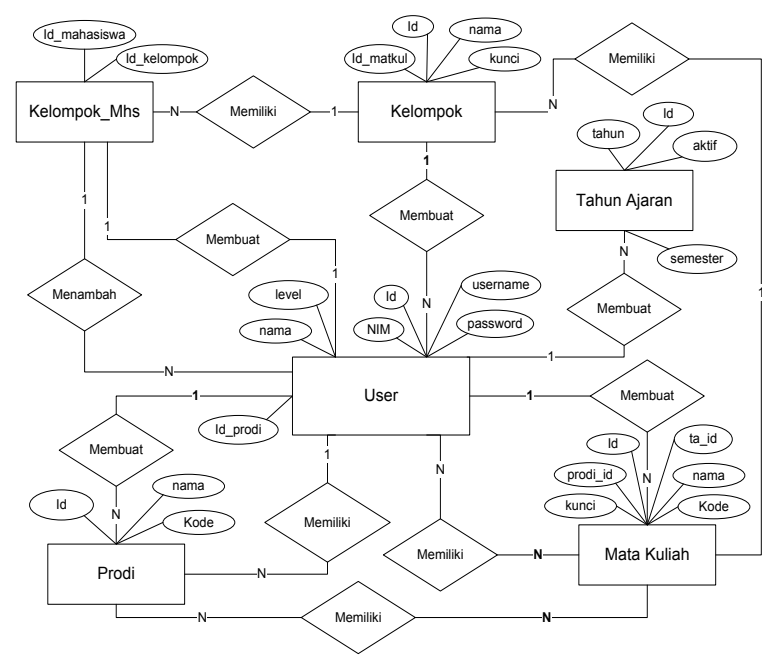

Gambar 8. ERD

Berikut penjelasan Entity Relationship Diagram (ERD) dimulai dari user membuat banyak, tahun ajaran, prodi, kelompok, kelompok mahasiswa dan mata kuliah. Prodi dapat memiliki banyak mata kuliah dan mata kuliah dapat dimiliki banyak prodi. Satu prodi memiliki banyak user tetapi user hanya dapat memiliki satu prodi. Mata kuliah dapat memiliki banyak user dan sebaliknya. user dapat membuat banyak kelompok yang memiliki banyak mata kuliah, menambah banyak mahasiswa pada kelompok, satu mahasiswa memiliki satu user.

\section{IMPLEMENTASI}

Hasil implementasi berdasarkan analisis dan perancangan adalah sebagai berikut:

\subsection{Halaman Login}

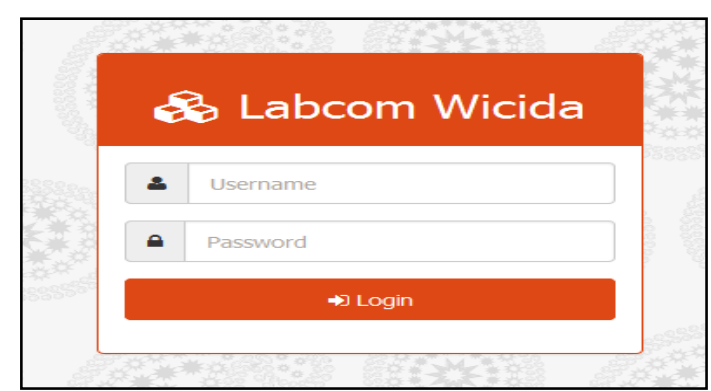

Gambar 9. Halaman Login

Halaman login untuk masuk ke halaman kepala lab, staff lab, asisten Lab dan mahasiswa dengan mengisi username dan password dengan benar pada form login lalu klik button Login. 


\subsection{Halaman Beranda}

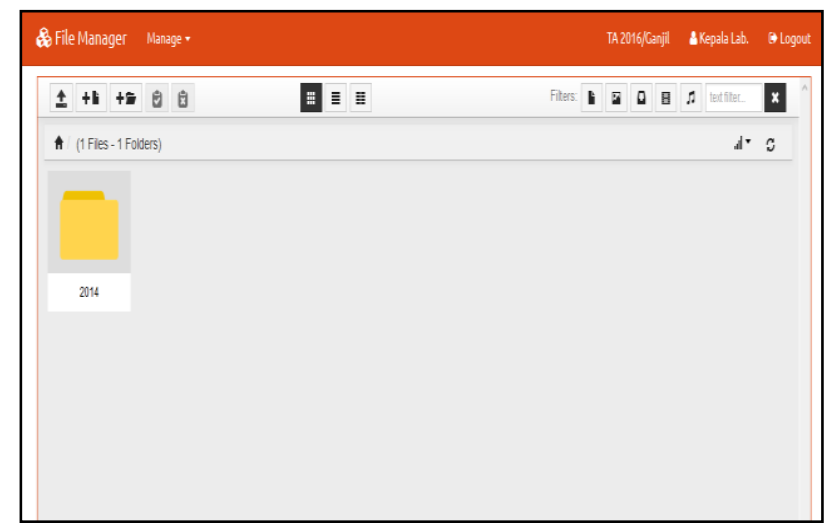

Gambar 10. Tampilan Halaman Beranda

Halaman awal berisi Menu manage user, manage tahun ajaran, manage prodi, manage mata kuliah, filter data berdasarkan prodi. Menampilkan daftar folder praktikum mahasiswa.

\subsection{Halaman Manajemen User}

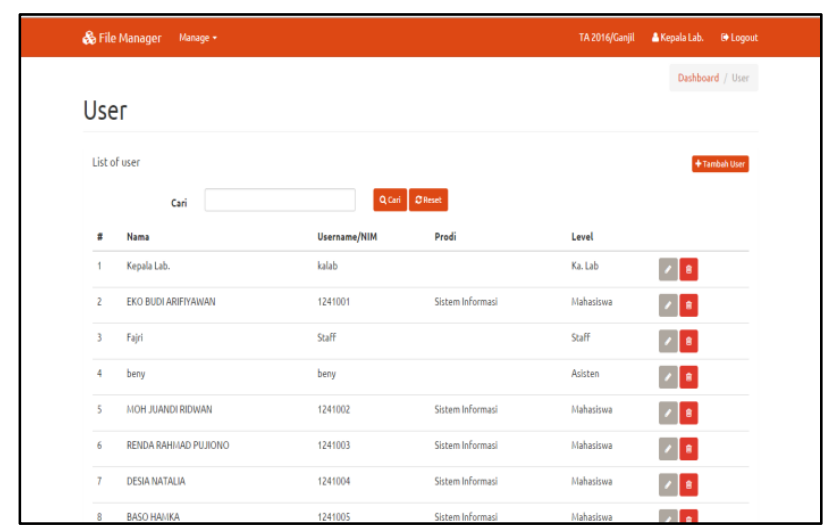

\section{Gambar 11. Tampilan Halaman Manajemen User}

Halaman manajemen user adalah halaman bagi kepala lab atau staff untuk menambah, mengubah dan menghapus user pada aplikasi.

\subsection{Halaman Manajemen Mata Kuliah}

Halaman manajemen mata kuliah adalah halaman bagi kepala lab atau staff untuk menambah, mengubah dan menghapus mata kuliah serta mendownload file praktikum berdasarkan mata kuliah

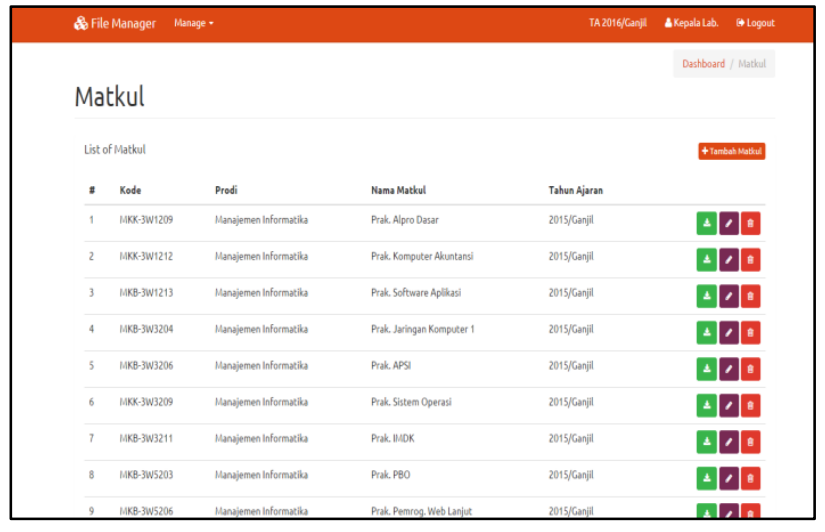

\section{Gambar 12. Tampilan Halaman Manajemen Mata Kuliah}

\subsection{Halaman Upload File Praktikum}

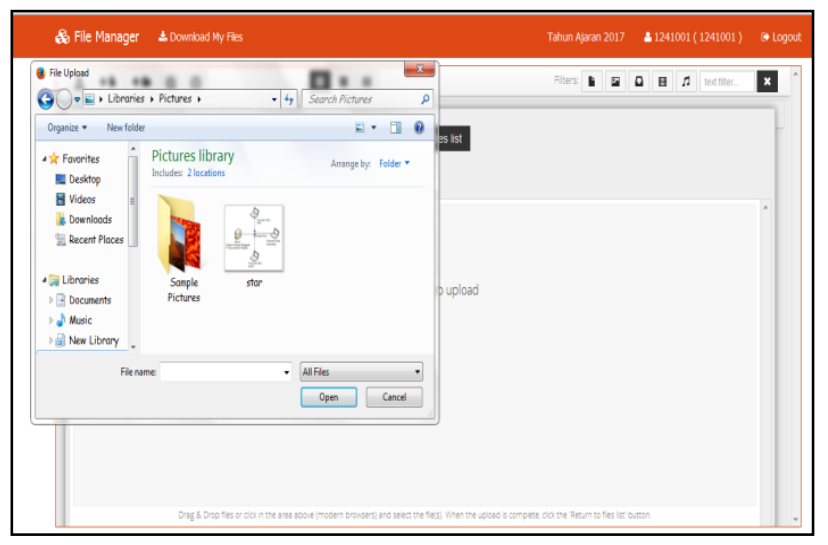

\section{Gambar 13. Tampilan Halaman Upload File}

Tampilan untuk mengupload file ke dalam folder dengan klik icon upload lalu pilih file yang ingin diupload lalu klik OK..

\subsection{Halaman Mata Kuliah}

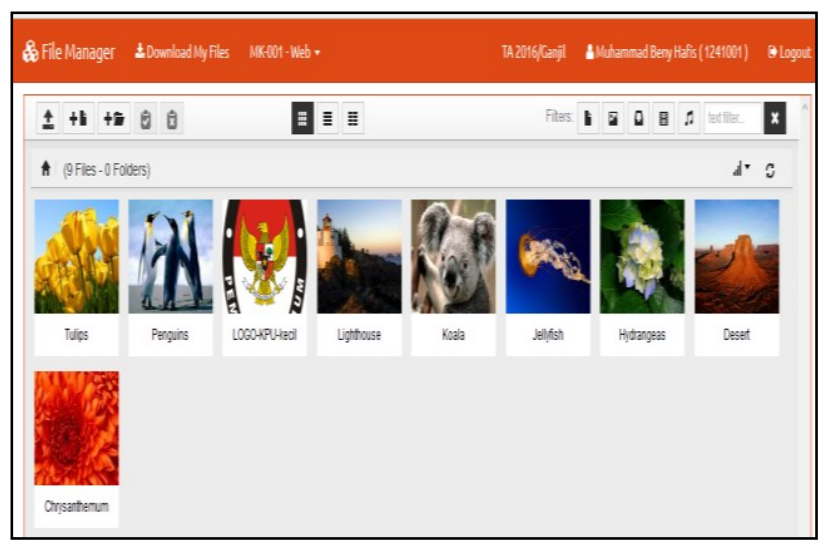

Gambar 14. Halaman Mata kuliah 
Gambar 14 pada halaman mata kuliah menampilkan file mahasiswa berisi daftar file praktikum mahasiswa berdasarkan mata kuliahnya. Dalam aplikasi Mahasiswa dapat mengupload file praktikum dan mendownload semua data praktikum yang diinginkan.

\subsection{Halaman Folder Telah Dikunci}

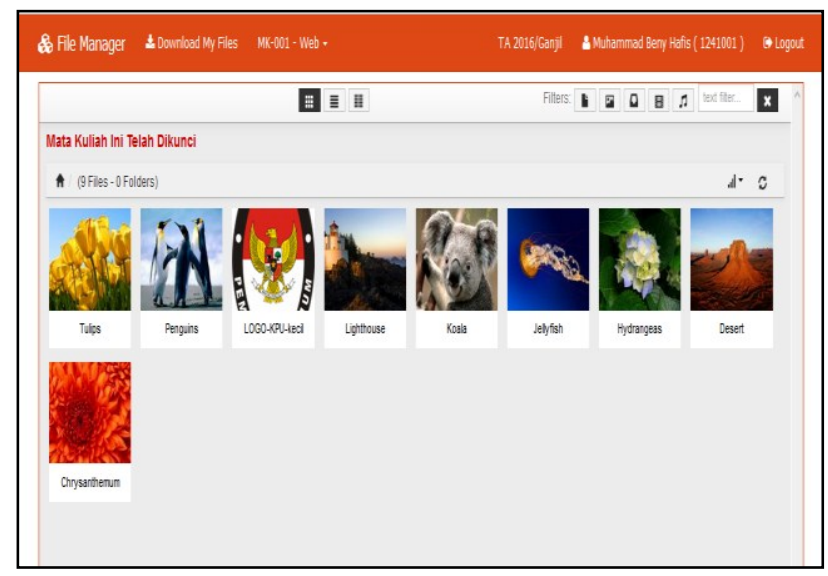

\section{Gambar 15. Halaman Folder Telah Dikunci}

Halaman folder mata kuliah yang telah dikunci berisi daftar file praktikum mahasiswa berdasarkan mata kuliahnya. Dalam aplikasi Mahasiswa hanya bisa mendownload semua data praktikum atau satu-satu file yang diinginkan

\subsection{Halaman Kelompok}

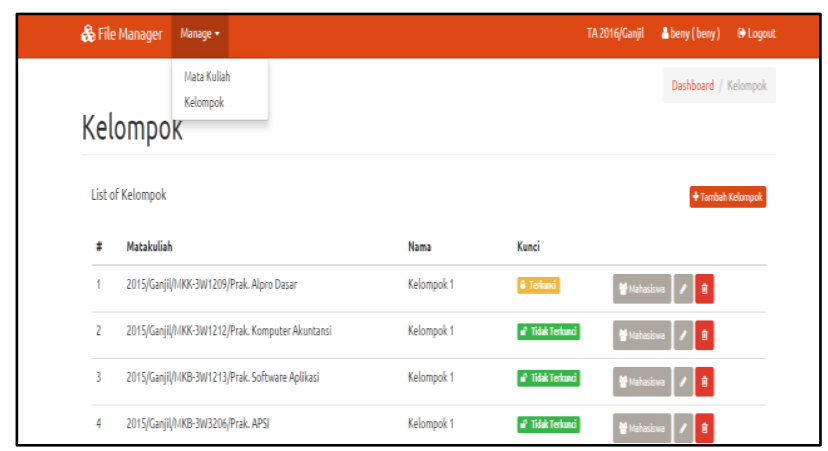

Gambar 16. Halaman Kelompok

Halaman manajemen kelompok adalah halaman bagi asisten lab untuk menambah, mengubah dan menghapus kelompok, mengunci kelompok dan menambah daftar mahasiswa pada kelompok.

\subsection{Halaman Daftar Mahasiswa Kelompok}

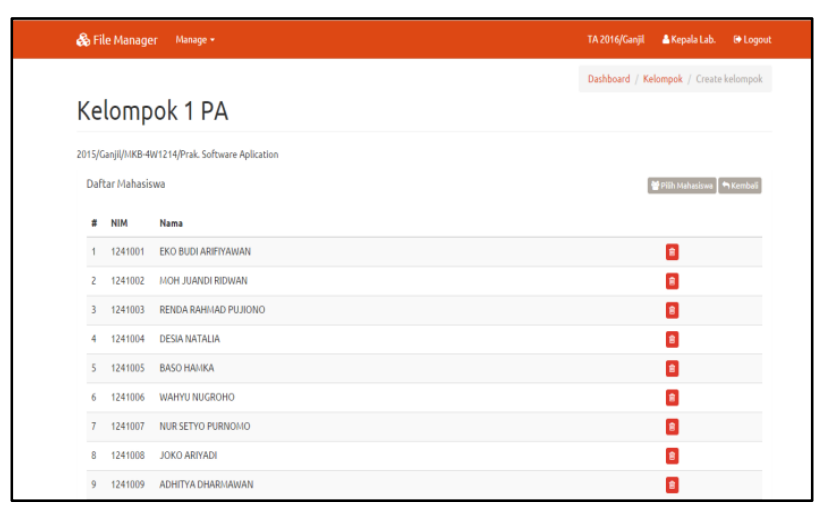

\section{Gambar 17. Halaman Daftar Mahasiswa Kelompok}

Halaman daftar mahasiswa kelompok berisi daftar mahasiswa pada kelompok praktikum dan bagi kepala lab atau staff untuk menambah dan menghapus data mahasiswa pada kelompok.

\subsection{Membuat Folder}

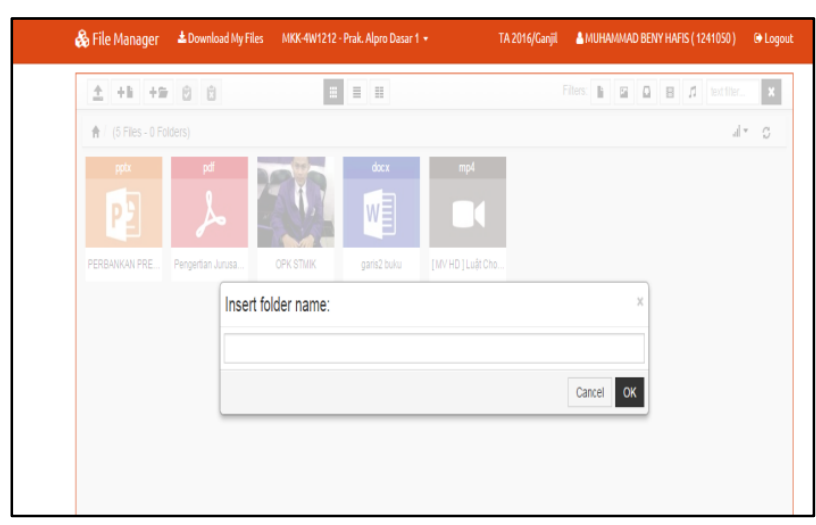

Gambar 18. Membuat Folder

Tampilan untuk membuat folder baru dengan mengetikkan nama folder yang diinginkan sesuai pada mata kuliahnya lalu klik OK.

\subsection{Halaman Beranda Mahasiswa}

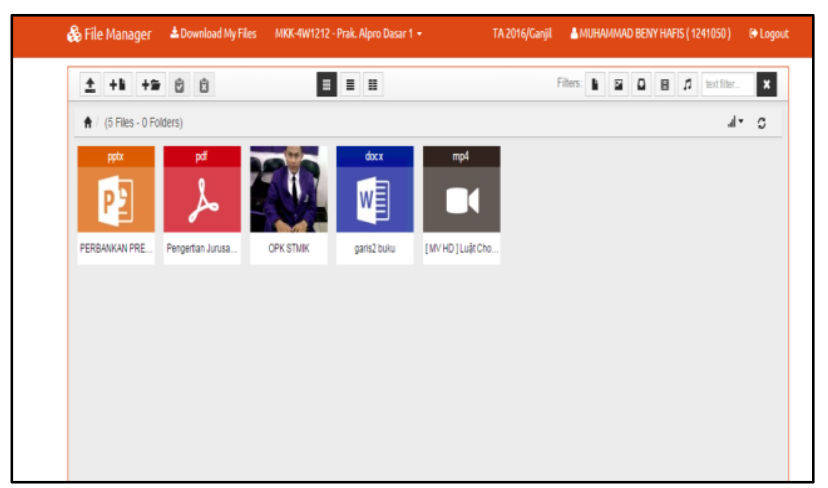

Gambar 19. Halaman Beranda Mahasiswa 
Gambar 19 pada halaman beranda mahasiswa berisi daftar folder praktikum mahasiswa. Dalam aplikasi Mahasiswa dapat mengupload file praktikum dan mendownload semua data praktikum miliknya.

\subsection{Halaman Tambah Mahasiswa Kelompok}

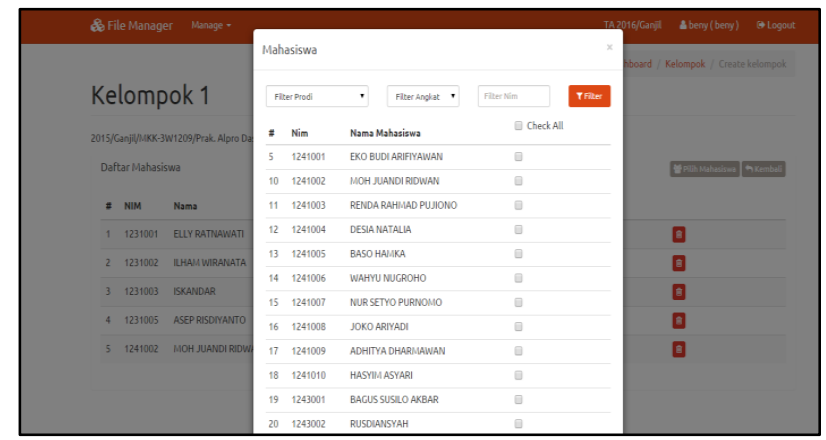

Gambar 20. Halaman Tambah Mahasiswa Kelompok

Halaman tambah mahasiswa pada kelompok adalah halaman bagi asisten lab untuk menambah data mahasiswa untuk diinputkan kedalam kelompok dengan memilih nama mahasiswanya lalu klik button pilih mahasiswa.

\subsection{Halaman Tambah Kelompok}

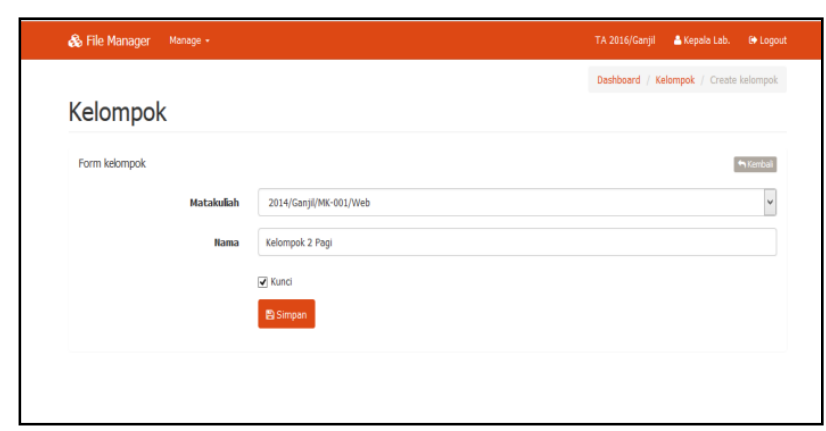

Gambar 21. Halaman Tambah Kelompok

Halaman bagi kepala lab atau staff untuk menambah data mata kuliah dengan menginput kode, nama mata kuliah, memilih prodi, klik centang kunci bila ingin mengunci mata kuliah lalu klik button simpan.

\subsection{Halaman Manajemen Prodi}

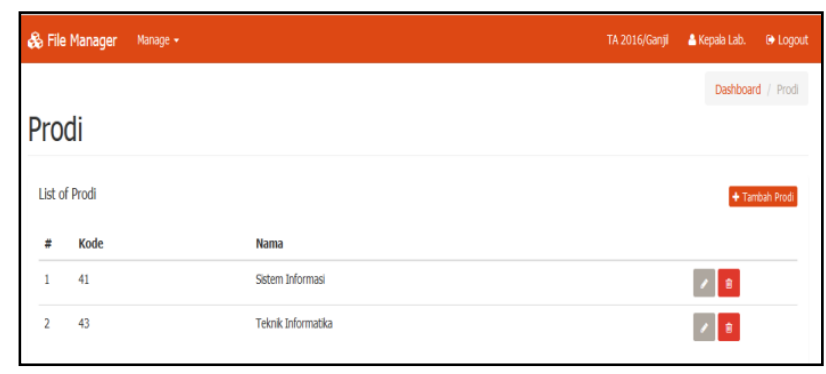

Gambar 22. Halaman Manajemen Prodi
Gambar 22 pada halaman manajemen prodi adalah halaman bagi kepala lab atau staff lab untuk menambah, mengubah dan menghapus data program studi pada aplikasi.

\subsection{Halaman Manajemen Tahun Ajaran}

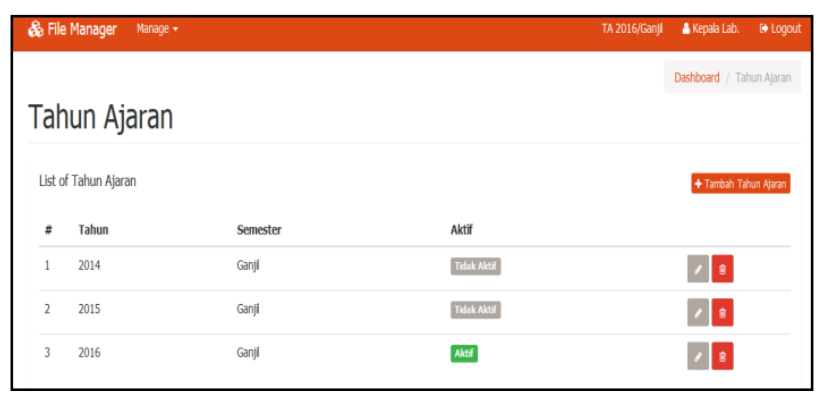

Gambar 23. Halaman Manajemen Tahun Ajaran

Halaman manajemen tahun ajaran adalah halaman bagi kepala lab atau staff untuk menambah, mengubah dan menghapus data tahun ajaran pada aplikasi.

\subsection{Halaman Edit Profil}

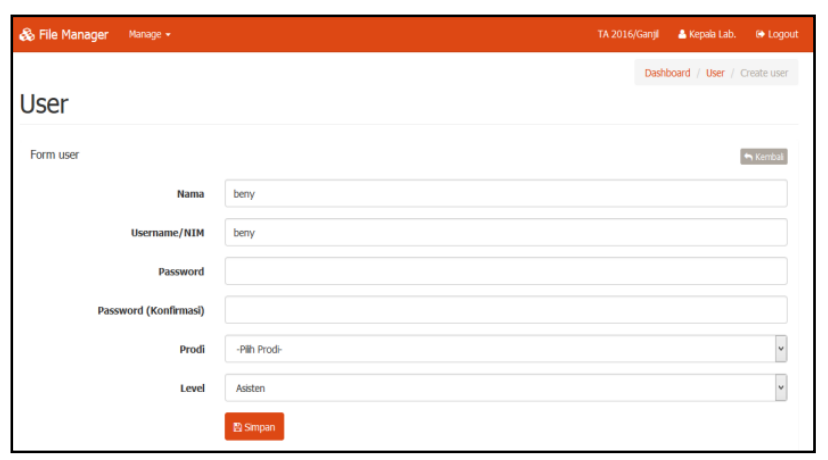

\section{Gambar 24. Halaman Edit Profil}

Halaman untuk mengubah data user dengan menginput nama, username atau NIM, password, konfirmasi password, memilih prodi dan menentukan level hak akses yang diinginkan lalu klik button simpan.

\section{KESIMPULAN}

Bedasarkan uraian pada bab-bab sebelumnya maupun pembahasan yang telah dikemukakan mengenai aplikasi pengelolaan data praktikum berbasis intranet maka dapat ditarik beberapa kesimpulan sebagai berikut:

1. Aplikasi ini digunakan sebagai penyimpanan data praktikum yang terstruktur dan lebih baik. Data praktikum disimpan berdasarkan NIM, mata kuliah dan program studi mahasiswa sehingga dapat memudahkan dalam pencarian dan pertukaran data praktikum.

2. Dengan adanya sistem ini mampu mengurangi penumpukan file dan folder praktikum pada komputer di laboratorium. Tingkat keamanan data praktikum lebih terjaga karena mahasiswa lain tidak dapat 
mengakses data praktikum milik mahasiswa lain dan folder dapat dikunci .

3. Aplikasi pengelolaan data praktikum berbasis intranet ini dibuat dengan menggunakan bahasa pemrograman PHP, CSS, HTML, Javascript dan MySQL sebagai databasenya dan alat bantu pengembangan sistem flowchart, DFD (Data Flow Diagram) dan ERD (Entity Relationship Diagram).

\section{SARAN}

Sesuai dengan kesimpulan yang telah dikemukakan, dapat kiranya penulis sampaikan beberapa saran yang dapat diterapkan antara lain sebagai berikut:

1. Aplikasi pengelolaan data praktikum ini dapat dikembangkan untuk penilaian praktikum

2. Aplikasi pengelolaan data praktikum ini dapat dikembangkan untuk absensi pada kegiatan praktikum.

3. Aplikasi pengelolaan data praktikum ini dapat dikembangkan berbasis online agar pertukaran data dapat dilakukan diluar laboratorium komputer.

4. Aplikasi pengelolaan data pratikum ini dapat dikembangkan agar dapat terhubung dengan SIAK yang ada di STMIK Widya Cipta Dharma sehingga tidak perlu menginputkan data-data sudah ada di SIAK.

5. Terdapat konversi data mahasiswa dan data matakuliah praktikum dari SIAK untuk Aplikasi.

6. Aplikasi dapat merekam/menyimpan data praktikum yang di kerjakan mahasiswa pada saat praktikum secara otomatis.

\section{DAFTAR PUSTAKA}

Hanif, Al Fatta, 2007, Analisis dan Perancangan Sistem Informasi, Yogykarta: Andi.

Ichwan, M., 2011, Pemrograman Basis Data Delphi 7 dan MySQL, Bandung: Informatika.

Inmon,W.H. (2005). Building The Data Warehouse Edisi Ke 4. Wiley Publishing, inc.

Jogiyanto, 2008, Pendekatan Terstruktur Teori dan Praktek Aplikasi Bisnis, Yogyakarta: Andi.

Kadir, Abdul, 2009, Mudah Menjadi Programmer PHP, Yogyakarta: Yeskom.

Kadir, Abdul, 2011, Buku Pintar JQuery dan PHP, Yogyakarta: MediaKom.

Kurniawan, Wiharsono, 2007, Jaringan komputer, Yogyakarta: Andi.

McLeod \& P. Schell, 2008, Sistem Informasi Manajemen, Jakarta: Penerbit Salemba Empat.

Prasetio, Adhi, 2012, Buku Pintar Pemrograman WEB, Jakarta: Media Kita.
Rosa \& Shalahuddin, 2011, Rekayasa Perangkat Lunak Terstruktur dan Berorientasi Objek, Bandung: Modula Bandung.

Santoso, Harip, 2007, Membuat Multiaplikasi M/Vb6, Jakarta: Elex Media Komputindo.

Shelly, Cashman, 2009, Discovering Computers (ed.3), Jakarta: Salemba Infotek.

Simarmata, Janner, 2010, Rekaysa Perangkat Lunak, Yogyakarta: Andi.

STMIK Widya Cipta Dharma, 2015, Buku Petunjuk Penulisan Usulan Proposal Dan Skripsi: STMIK Widya Cipta Dharma.

Suyanto, Asep, 2007, Web Design Theory and Practices, Yogyakarta: Andi Offset.

Tantra, Rudy, 2012, Manajemen Proyek Sistem Informasi, Yogyakarta: Andi.

Wicaksono, Yogi, 2008, Membangun Bisnis Online dengan Mambo, Jakarta: PT. Elex Media Komp. 